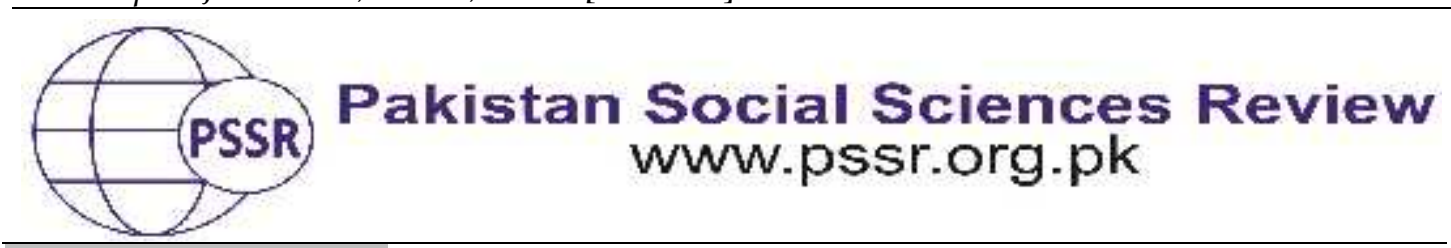

RESEARCH PAPER

\title{
Ideological Reformation in a Society through the Linguistic Monopoly Depicted in the Advertisements in Pakistan
}

\author{
Hafsa Naseer ${ }^{1}$ Nazneen Zahra ${ }^{2}$ Hina Basheer ${ }^{3}$
}

1. Research Scholar, Department of English, Bahauddin Zakriya University, Multan, Punjab, Pakistan

2. Lecture, Department of English, University of Gujrat, Gujrat, Punjab, Pakistan

3. Research Scholar, Department of English, Bahauddin Zakriya University, Multan, Punjab, Pakistan

\begin{tabular}{|c|c|}
\hline PAPER INFO & DSTRA \\
\hline $\begin{array}{l}\text { Received: } \\
\text { March 06, } 2021 \\
\text { Accepted: } \\
\text { June 05, } 2021 \\
\text { Online: } \\
\text { June 10, } 2021\end{array}$ & $\begin{array}{l}\text { The objective of this study is to explore how advertisements } \\
\text { influence human ideologies, shape their ways of thinking and } \\
\text { have influential impact upon their behavior. It also throws the } \\
\text { light that without the proper use of language; we cannot } \\
\text { transmit our message through advertisements. Studies on the }\end{array}$ \\
\hline $\begin{array}{l}\text { Keywords: } \\
\text { Advertisements, } \\
\text { Advertisers, } \\
\text { Consumers, } \\
\text { Critical Discourse } \\
\text { Analysis (CDA), } \\
\text { Language, } \\
\end{array}$ & $\begin{array}{l}\text { topic reveal that advertisers have always used words that } \\
\text { influence the audience; manipulation of language helped the } \\
\text { advertisers to divert the focus of their targeted audience } \\
\text { towards their desired destination, hence generating a desire to } \\
\text { buy the product. For this research Fairclough's three } \\
\text { dimensional model comprising description, interpretation and } \\
\text { explanation is used for Critical Discourse Analysis (CDA) of }\end{array}$ \\
\hline $\begin{array}{l}\text { *Corresponding } \\
\text { Author } \\
\text { hnaeem98@gmail. } \\
\text { com }\end{array}$ & $\begin{array}{l}\text { three ads (from television commercials) for interpretation. The } \\
\text { findings of the study show, how in Pakistan the language } \\
\text { depicts its role in forming ideologies through advertisements. It } \\
\text { further elaborates how language persuades people; hence it } \\
\text { generates a desire in the audience to buy the product being } \\
\text { advertised. The research further elaborates how these } \\
\text { advertisements are playing a vital role in changing our society } \\
\text { and culture. }\end{array}$ \\
\hline
\end{tabular}

\section{Introduction}

Capitalists manipulate language for their gains. Language has the power to reform behavior of general masses. It generates desire to act according to the wishes of advertisers and to accept the views of the capitalists. A language is the representative of the cultural values, norms, ethnicity and psychology of its speakers. Hence, the advertising agencies use language to gain their economic motives. They higher expert staff formulate effective strategies for their success. According to Leeuwen, Advertisements take us to the world of glamour and the allusions to the prohibited pleasures; the words project our need, the qualities of a 
product compel us to buy, it also explains the source of its attainment (Leeuwen, 2008, p. 136).

The major aim of advertisers is to attract the attention of the consumers and change their ideology. Hence, this strategy promotes their services and goods. So, they adopt effective communication strategies to achieve their goals. To win the trust of the consumer groups, they have to employ tactful linguistic strategies. However, an advertisement being a promotional agent also contributes as a new piece of creation. Which either represents the culture of the prevailing society or of the text makers. Although a commercial remains alive for a short period of time but it's after effects are always long lasting (Goddard, 2001, p.3-4). The present research paper throws light on the procedure of attracting attention of the consumers through manipulated language of advertisements and how it affects a society and its culture. This study takes help from Fairclough's three dimensional models to show the impact of advertisements upon Pakistani culture and society

The aim of this research paper is to understand the language of different advertisements, which we see in our newspapers and T. V. channels. It shows how by using "one line statement" or "a simple bolded phrase" they grab the attention of a huge consumer group and compel them to buy their products (Ahmed, 2011).

\section{Advertisements and Critical Discourse Analysis (CDA)}

According to Van Dijk (1985) Critical Discourse Analysis can be considered as analytical discourse. Wherever there is the existence of a society, community and group is found discourses are found there. With the passage of time discourses are changing, older ones are replacing with the advanced discourses. The examples of these discourses include, advertising discourse, media discourses, political discourses, Marxist discourses, feminist discourses, gender discourses, and environmental discourses and so on. While discussing about the advertisements the ideas of beauty, perfection, smartness, personal care and color are depicted in an influential way to impress the targeted audiences. Whatever is portrayed in commercials and media is presented in such an attractive that people consider it a reality and want to purchase the presented product considering it as their need (Kaur, Arumugam, and Yunus, 2013).

\section{The Role of Ideology in Advertisements}

Ideology is abstract and we have an ideology about every point in our lives consciously or unconsciously. Ideology comes from our inner self; it depicts our thinking and demarks us in a certain group having the same ideology as ours. It is the voice of our, heart, mind and soul. Hence difference ideologies form a different personality. An ideology makes us a distinguished personality yet part of a bigger whole. If we want to analyze an ideology there is a need to go in the pass history to evaluate it (Foucault, 1980). On the past history, on the basis of evidences we decide about the credibility of an ideology. He depicts if there is a contradiction between our present ideologies and existed in the past history then there is a doubt about the 
authenticity and justification of an ideology. According to Fairclough (1992), a text is defined by an ideology, having a hidden agenda or ideology and a text joins the creator, observer or listener and interpreter. Whenever there is a change prevalent in a society it comes into existence having an ideology behind it. So, ideology can also play a role of social reformer. Russian revolution, French Revolution and the creation of Pakistan are the examples of the changes due to ideologies.

Like the role of ideologies in every field of life, an ideology plays a vital role in the presentation of commercials. Every commercial is presented in print or electronic media having certain ideology behind it. Advertisers present the selected content having some ideology and need to buy the products. The ideologies presented in commercials are usually associated with personal care, home, decoration, beauty, smartness and self development.

\section{Literature Review}

Language can never be neutral and naïve. Through language an individual or a group of people can have power. 'Technologies of power' is a phrase formulated by Michel Foucault (1980). According to him the concept of power in the field of technology is flourished during $18^{\text {th }}$ and $19^{\text {th }}$ century. He also depicted about power, as the language used by the people who hold a powerful position, they manipulate it and use it for their own purpose, and so social inequality is created.

Alperstein (1990) projects, the language presented in advertisements influences the life of an individual as well as social life. Sometimes people use the same phrases in their daily lives. He has unfolded the strategies; the advertising agencies follow to enhance the sale of their products. He emphasized the relationship of the written text and the images to elevate the impact of advertisements upon the changing culture of a society.

However there are various kinds of advertisements, according to their form, presentation, and images used. There are both printed advertisements and advertisements displayed on electronic media. Vestergaard and Schroder (1985) explained, advertisements can be divided into two types 1) commercial advertising and 2) noncommercial advertising.

Rosul (2007) explained, the hidden agenda ingrained in advertisements. She has also clarified how advertisers manipulate the language, when they launch beauty products both for women and men. Despite that, Vandijk, (1985) explains, the phenomenon of advertising as an agent of influencing the minds of people. Leech, (1966) calls advertising as "loaded language", and its purpose is to motivate people to act accordingly. 


\section{Material and Methods}

\section{Theoretical Framework}

The research is about the impact of the language of advertisement upon people. The data for this research paper is collected from television commercials to investigate the answers of the research questions. Fairclough's three dimensional model is selected as a theoretical framework to analyze the text of the advertisements for this research paper.

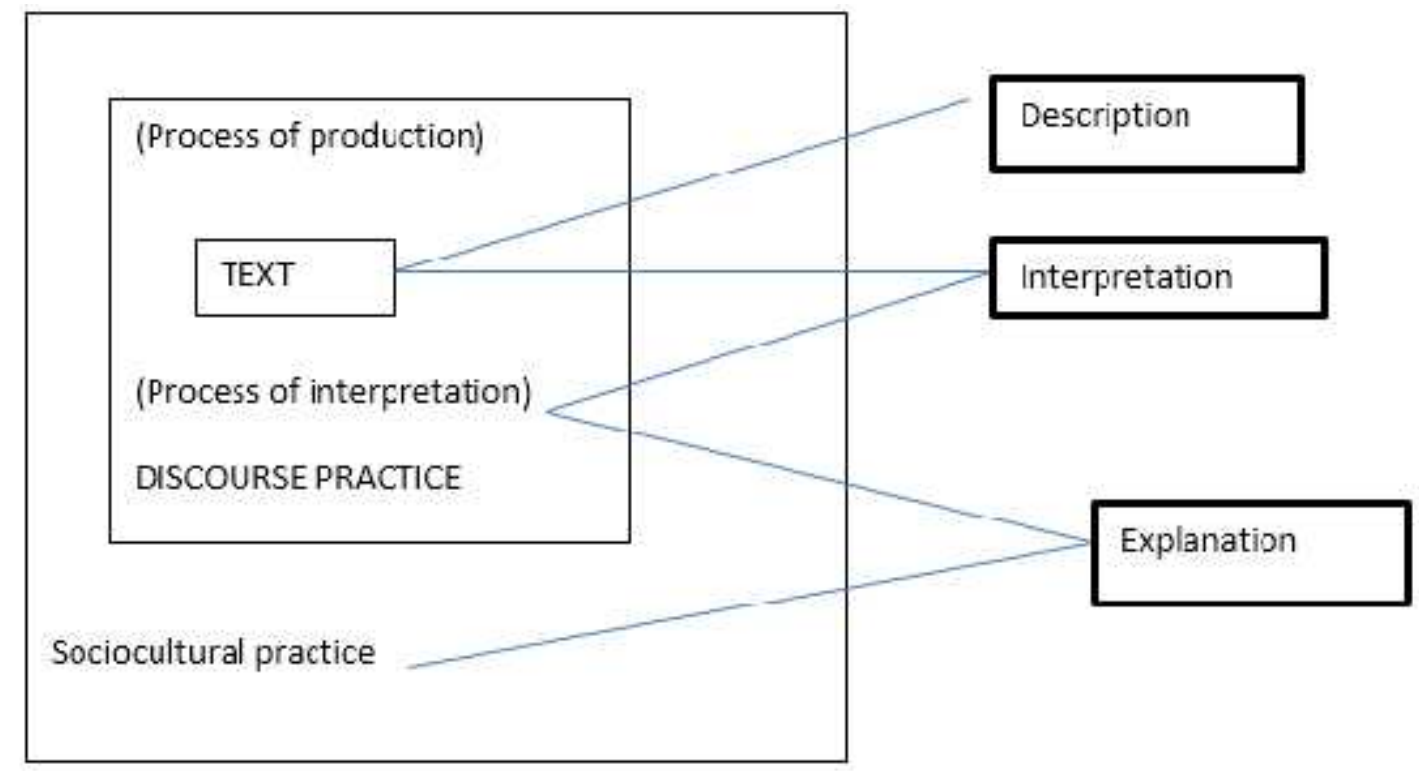

Fig-1: Flairclough's Three-Dimensional Model (Flairclough, 1995,p.98)

In his model Fairclough explains 'Text' is of two forms, written and oral, and oral text can be only spoken text (radio) or can be both spoken and visual (television), 'discourse practice' is the process of text creation and distribution, and 'socio-cultural practice' is how it becomes fit in cultural and social practices of a given community. Text analysis is the interpretation the apparent text and its underlined meaning. Fairclough (1992) prescribed; texts can be explained in different ways. Production, distribution and consumption of the text are collectively considered as discursive practice. The relation between the text owners and the text of creation or production is also focused in discursive practice. . Discursive practice also focuses on the consumption of the text. The discourse of the texts has control over the text interpretation (ibid). The analysis of discourse shows a strong relation among language, power and ideology. Hence, discourse plays a vital role in forming the ideologies of the people.

The data is collected from two sources one is 'You Tube' and the other is a commercial from the print media. The first commercial is of "Fair and Lovely" a commercial of a beauty cream, second commercial as the previous one is from television commercial that is of "Surf Excel" a home care beauty product. The third 
commercial is also from television is of "Zong $4 \mathrm{G} \mid$ " representing the everyday necessity.

\section{Results and Discussion}

Images in the ads also give messages despite the monopolistic use of language. Following are some of the ads taken from television media. First commercial is of a famous beauty product Fair and Lovely. Latest commercial is selected for this purpose in this commercial Sajjal Ali a famous actress and model is projecting the benefits of using the new Fair and lovely cream. As it does not only brightens the complexion but gives HD Glow. A glow that is more than just beauty. Every time a new concept and novelty is added in the commercial to attract the attention of its customers. Different color combinations are used to make the product attractive. As in this commercial different fonts are used for fair and lovely and HD Glow. Despite different fonts, different colors are used in the image shown.

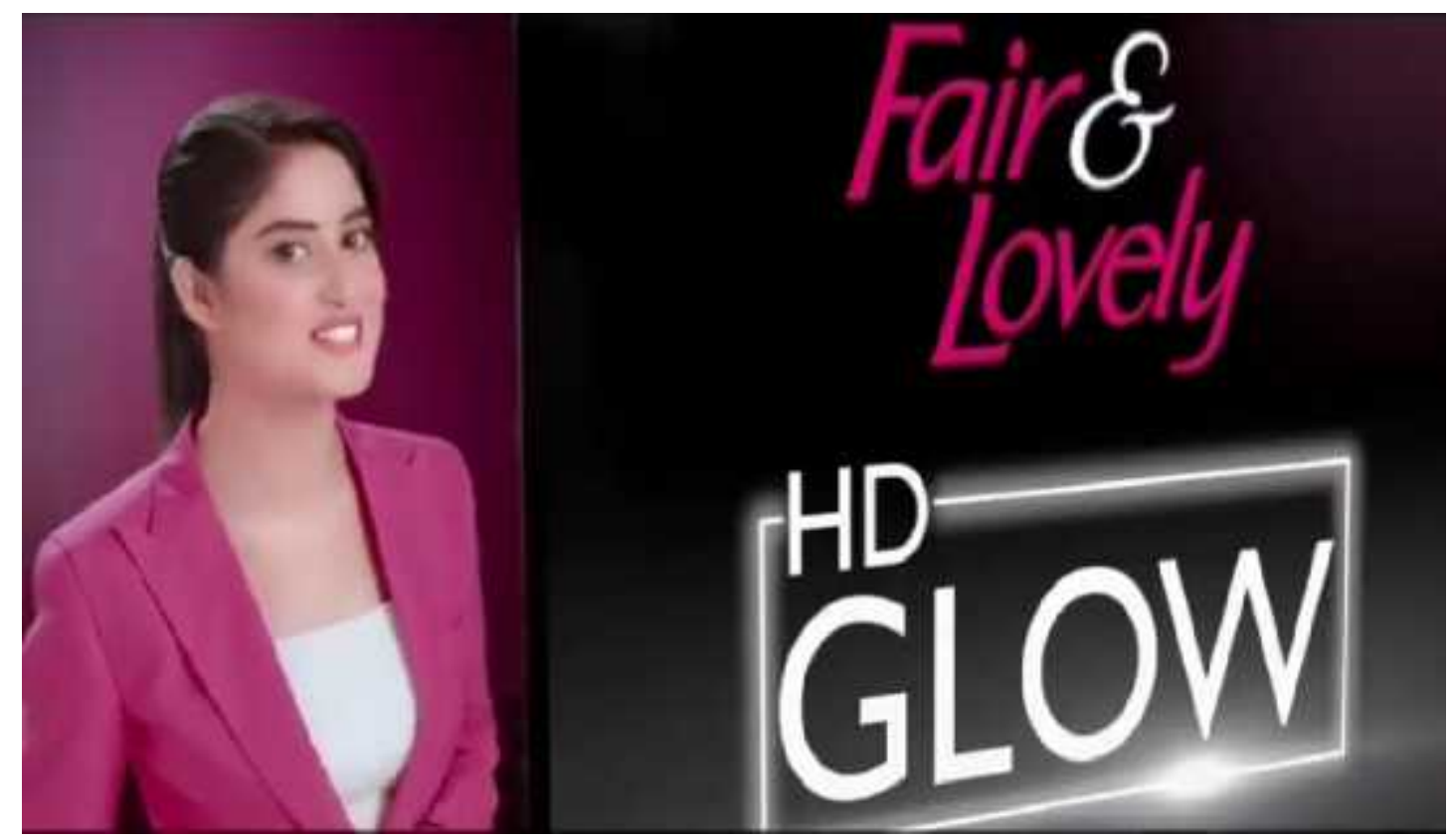

Figure2: Advertisement of "Fair and Lovely"https://www.youtube.com/watch?v=KTSskdJHFHY

A famous and renowned personality is selected to present the ideology of the company. So, in the present advertisement most of the people, who know this personality, would definitely listen to her carefully. As Sajjal Ali can be the ideal for many girls in Pakistan. Ideal perfect beauty as, there are certain set standards in our society that a girl should be smart, white complexioned, tall and educated. Through commercials same standards can be seen in the projected personalities. As in the present commercial the model is smart, attractive and beautiful. When she gives the 
thought to the young girls how they can also be beautiful and fair by using this product. They desire it and want to buy it. So, the objectives of the owners gain success. It produces competition in the market.

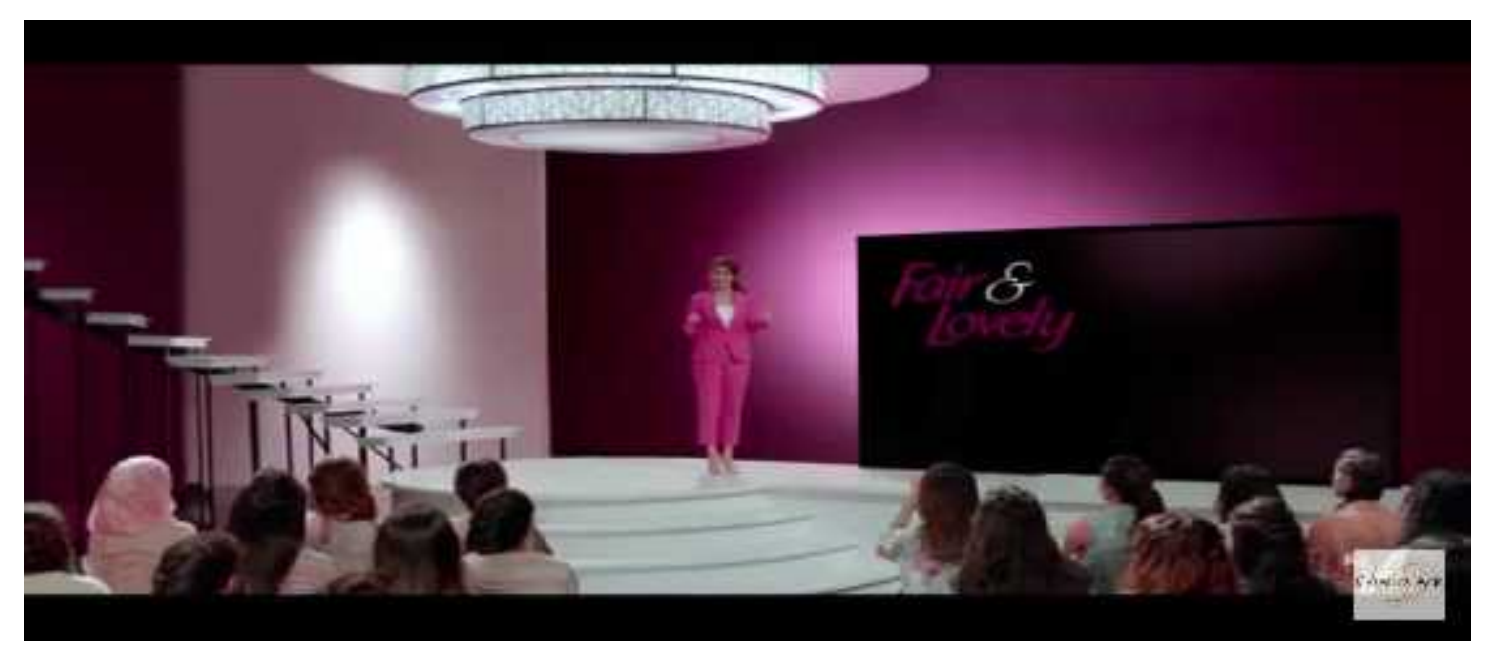

Figure3: Advertisement of "Fair and Lovely" https://www.youtube.com/watch?v=KTSskdJHFHY

In the upper figure the model has shown coming out of the glow and light and in the scene some girls are sitting as audience are of the same age as the model. They are listening to the model with keen interest. It shows the targeted audience is almost of the same age as the model's age.

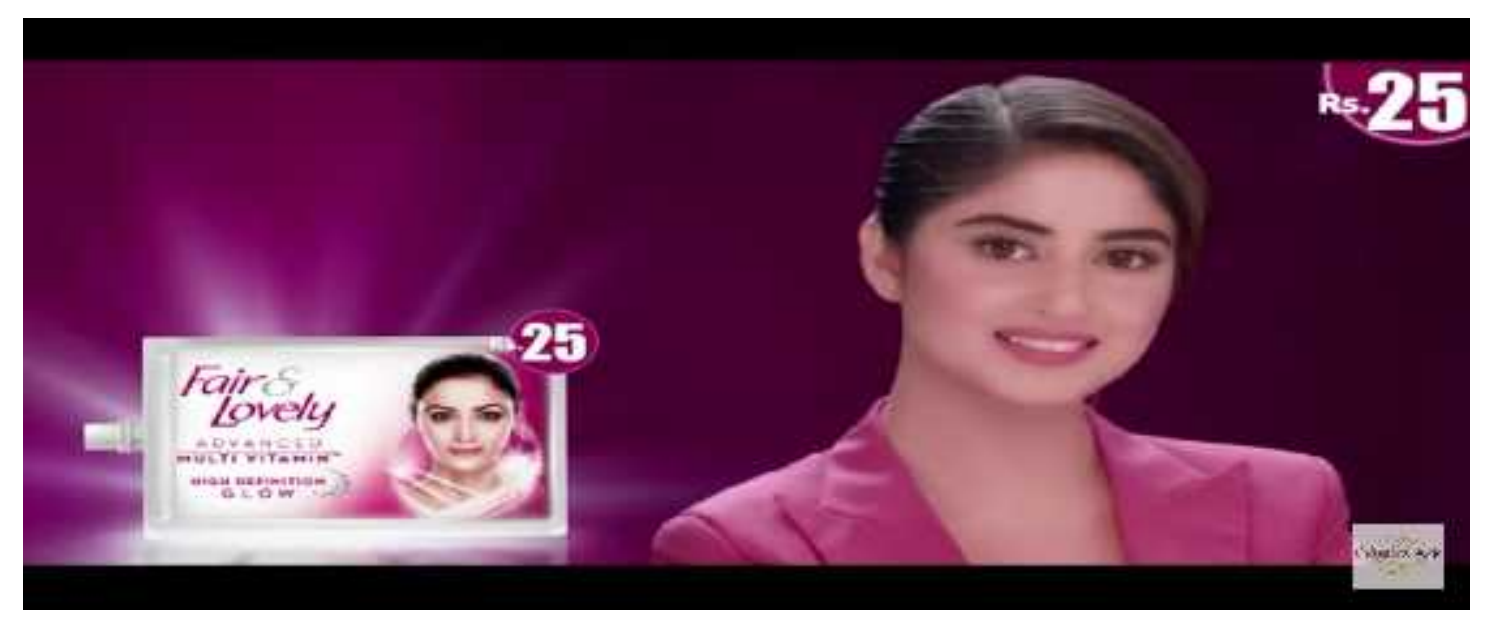

Figure4: Advertisement of "Fair and Lovely" https://www.youtube.com/watch?v=KTSskdJHFHY

Packaging is always attractive and sometimes the price shows it's cheap and can easily be brought. It is also a strategy used by the advertisers so, every person who desire it can purchase it. Qualities of the product are shown on the cover. As it 
is shown on the cover Advanced Multi Vitamin formula, High Definition Glow. Some words are written in bold like GLOW is written in bold letters to emphasize its importance. Color and complexion of the model is shining and glowing hence it ultimately generates a desire in the customer to purchase it if she wants to be fair and beautiful. She will idealize the model and want to be like her this will urge her to buy the product. The same strategy is employed by every beauty product. So with the passage of time with the advent of new beauty creams the standards of dream beauty are also changing. By watching the portrayal of elite culture and ethics our lower and middle class young girls are becoming the victims of oppression and depression. Ideology of an ideal life for a young girl have changed a lot during the last two decades, due to the electronic media projections of new advertisements every other day.

So as Fairclough's theory presents three levels text of the advertisement discourse presents the ideology of beauty. The production of the commercial is especially made to influence the ideology of the younger girls. In discourse practice its interpretation in reality generates desire in consumers to buy the product. Hence its explanation in socio cultural practice is also seen in our everyday life in Pakistan.

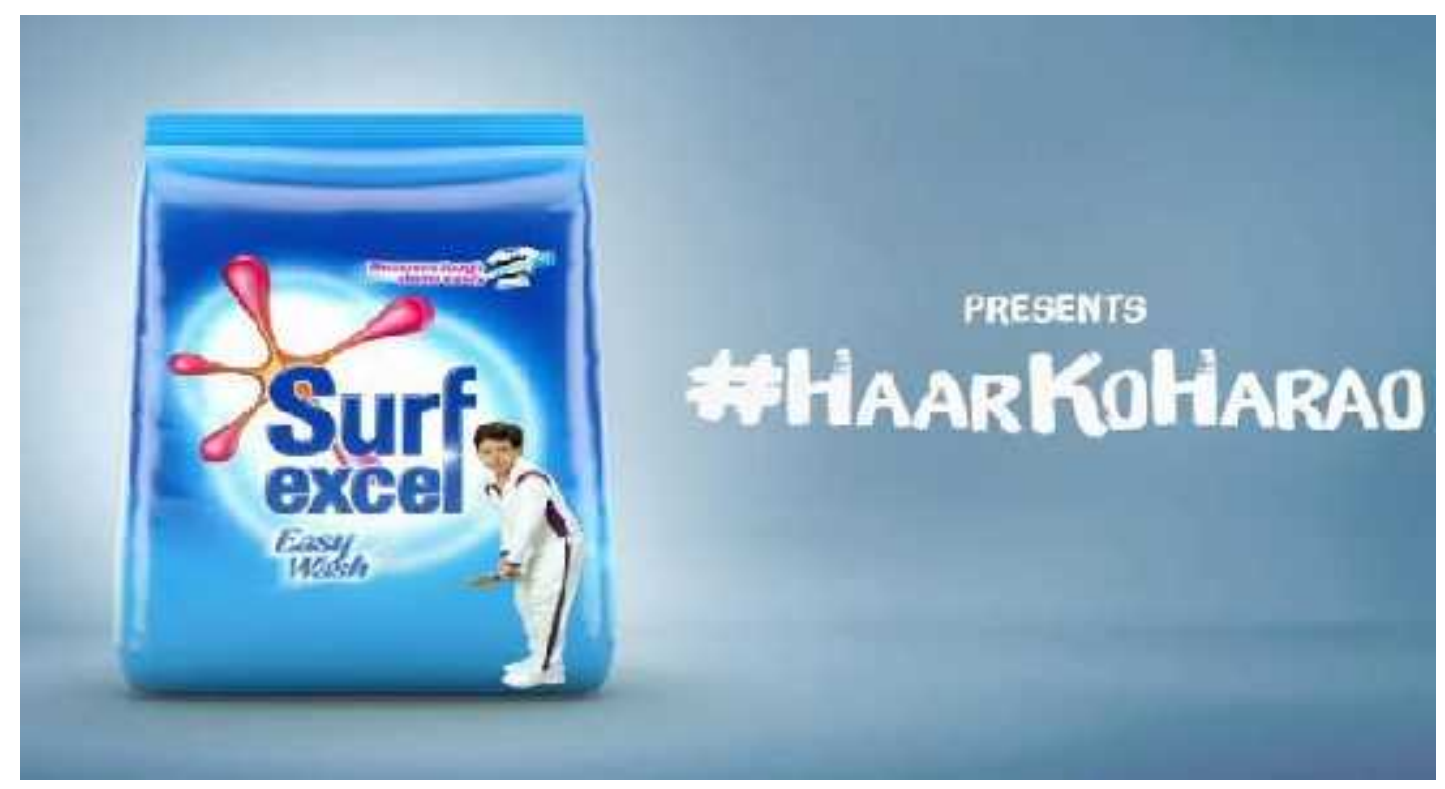

Figure 5: Commercial of Surf Excel

https://www.youtube.com/watch?v=YicuKTFPxX0

Second commercial is of Surf Excel a leading detergent brand in Pakistan, which has changed the ideology about cloth stains by proclaiming daag to achy hoty hain (cloth stains are good). Previously this practice was discouraged by the parents but now in previous some years Surf Excel has changed this ideology. In 2016 during the holy month of Ramzan the advertisers of this brand launched the phrase Kisi ki maded krny mai ager daag lg jain to daag to achy hoty hain (if your cloths gets dirty by 
helping someone, your cloth stains are good). In 2017 during the same month they launched another advertisement proclaiming Khud ko bhula $k$ agr doosron ka khyal rakhny mai daag lag jain to daag to achy hain (if your cloths get dirty by thinking about others and negating youself, then cloth stains are good).

Likewise in 2018 during Ramzan another advertisement by Suf Excel came on T.V. explaining, Apno ko kareeb laany main agr daag lag jain to daag to achy hain (if your cloths get dirty, while bringing relatives close, cloth stains are good). Hence, in the present year, another advertisement by the same brand was launched projecting the key phrase Ehsaas $k$ izhaar main agar daag lag jain daag to achy hain (if your cloths get dirty by expressing your feeling for good cause, cloth stains are good). Thus there are other phrases like "Falling gets me dirty, falling makes me learn". Haar ko haraao (defeat your defeat). The purpose of the advertisers is to enhance the sale of their product, while accomplishing their key task they are changing the ideology of Pakistani society that dirt is good if you get it by helping someone, they are doing this through the monopoly of language

So the ideology of social change is projected in this advertisement where the phrases of the texts are so arranged that its interpretation and explanation has made the stains good not bad as was previously conceived. So commercials have power to change the set ideologies through the affectivity and ideology presented in the making and proceeding, interpretation and explanation of the text.

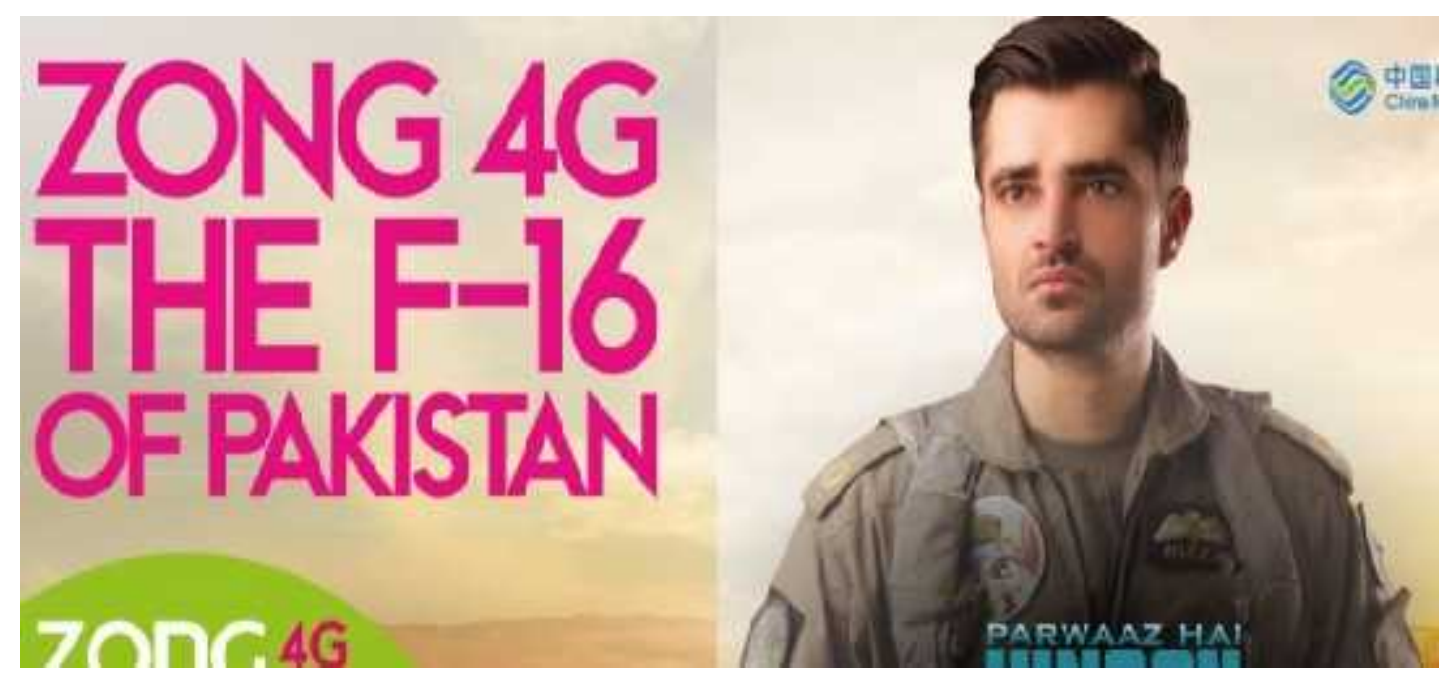

Figure 6: Advertisement of Zong 4G https://www.youtube.com/watch?v=L6UsyEunG5U

Another advertisement of Zong mobile network has been taken from television commercial. The subsequent image reprints the different colors of different words despite that different fonts are used to emphasize certain wods . like ZONG 4G THE F-16 OF PAKISTAN .All the words are capitalized to show the importance of the phrase, despite that it shows the metophor used for Zong is F-16 which is a jet used by Pakistani army and famous for its speed. And obviously every 
Pakistani has an emotional attachment with the army. By arousing the sentiments of the society advertisers want to achieve their hidden agendas as proclaimed by Fairclough. There is an apparent meaning of the text, there is an interpretation of the text and its purpose and thirdly there is the implication of the text as sociological practice. A NEW DREAM a phrase in the advertisement also compels the reader to think about it and act according to the wishes of the planners.

The text and dialogues are so projected, like F-16 shows the speed and power it is related with the speed of the internet. It is fast like F-16, prominent personality of Hamza Ali Abbasi is shown in the commercial being charismatic so in social practice the explanation of the commercial demands this network to be used in everyday use. A new dream of fast speed is projected in the commercial.

\section{Results and Discussion}

As it is evident from the above analysis the leading brand commercials are selected for data analysis. The ideologies of beauty, home care and daily needs are chosen by the advertisers working on the platform of commercial market in Pakistan. For the interpretation of these advertisements Fairclough's three dimentional, model of Critical Discourse Analysis is adopted.

The first commercial is of "Fair and Lovely" clearly shows the ideology of beauty is adopted by the producers of the text to influence the thoughts of our younger lot. They after watching feel it's their desire to purchase it. Its explanation and interpretation is done in an influential way.

Secondly, the advertisement of "Surf Excel" presents the ideology of home care, with revolutionary change in the idea of stains. As stains were considered bad but now trend is changing to consider these good for the personality development, confidence and learning of the kids. Its dialogues are arranged in such an impressive manner that sometimes its interpretation and explanation demands ethical considerations, for stains being good if these come to you while doing any good deed, or helping someone.

Lastly the advertisement of Zong $4 G$ is especially designed to influence the ideology of daily need. So the ideologies of beauty through Fair and lovely is projected. Where targeted audience is women. While through the advertisement of Surf Arial the ideology of home need is expressed. Where parents now want their kids to learn by doing, by helping and if they get some stains these are good. They are good too because can be washed with Surf Excel. The same strategy is adopted in the third advertisement. The advertisers are spending a lot of money to gain their motifs in the market.

\section{Conclusion}


By the above discussion it is evident that monopolistic role of language in forming ideologies, in the advertising agency cannot be denied. Advertisers choose prominent and charismatic personalities for their products that a society generally admires. Despite this, capitalists use effective language to attain their ends, for this purpose they play with the emotions of the masses. The more the people feel associated with the personality projected in the advertisement the more they will follow it (sutherland, 2008). Advertisements not only advertise the agenda of its producers but also play a key role in changing their ideologies.

\section{Recommendations}

Critical Discourse Analysis spanning on a lot of ideologies. Every now and then innovations in this field are prevalent. By getting idea from our study the scholars and researchers can analyze the advertisements from Marxist, feminists, capitalists' ideologies. They can use the qualitative analysis plus quantitative analysis to enhance the affectivity and different variants. 


\section{References}

Ahmed, S. M. S. (2011). Historical Perspective and Evaluation of Advertising Firms in Bangladesh.European Journal of Business and Management, 3(5), 65-68.

Alperstein, N. M. (1990). The Verbal Content of TV Advertising and Its Circulation in Everyday and Men.( unpublished M.A. Dissertation). East West University, Australia.

Arens, W.F (2002).Contemporary Advertising.(8thed.).New York, NY: McGraw-Hill.

Fairclough, N. (1992). Discourse and Social Change. Cambridge, UK: Polity Press

Fairclough, N. (1995). Media discourse. London: E. Arnold. (Vol. 1): Sage.

Foucault, M. (1980). Power/Knowledge: Selected Interviews \& Other Writings 19721977, Pantheon Books, New York, NY.

Geoferry N. Leech, (1966). English in advertising: a linguistic study on advertising in Great Britain. English Language Series, General Editor, Randolph Quirk. Longmans, Green and Co., London.

Goddard, A. (2002). The language of advertising: Written texts. London: Routledge.

Kaur, K., Arumugam, N., \& Yunus, N. M. (2013). Beauty product advertisements: A critical discourse analysis. Asian Social Science, 9(3), 61.Trans.

Leeuwen, T.V.(2008). Discourse and Practice: New Tools for Critical Discourse Analysis. New Life. Journal of Advertising, 19(2), 15-22.

Rosul, S. (2011). A Critical Discourse Analysis of Fairness-Product Advertisement for Women and Men. East West University: East of West University.

Schiffrin, D., Tannen, D., \& Hamilton, H. E. (2001). The Handbook of Discourse Analysis. Blackwell Publishers.

Sutherland, M. (2010).Advertising and the Mind of the Consumer: What Works, What Doesn't, Routledge.

Van Dijk, T. A. (1985). The handbook of discourse analysis. London: Academic Press.

Vestergaard, T \& K Schroder (1985). The Language of Advertising. Oxford: Basil Blackwell. 